\title{
A Telemonitoring Programme in Patients with Heart Failure in France: A Cost-Utility Analysis
}

\author{
Mégane Caillon ( $\square$ mcaillon@amgen.com) \\ Amgen \\ Rémi Sabatier \\ $\mathrm{CHU}$ de Caen Normandie \\ Damien Legallois \\ $\mathrm{CHU}$ de Caen Normandie \\ Laurène Courouve \\ Cemka \\ Valérie Donio \\ Cemka \\ Florence Boudevin \\ Amgen \\ Thibault de Chalus \\ Amgen \\ Karine Hauchard \\ Normand'e-santé \\ Annette Belin \\ $\mathrm{CHU}$ de Caen Normandie \\ Paul Milliez \\ CHU de Caen Normandie
}

Research Article

Keywords: telemonitoring, France, heart failure, cost-effectiveness.

Posted Date: December 3rd, 2021

DOI: https://doi.org/10.21203/rs.3.rs-1106867/v1

License: (c) (i) This work is licensed under a Creative Commons Attribution 4.0 International License. Read Full License 


\section{Abstract \\ Background}

Certain telemedicine programmes for heart failure (HF) have been shown to reduce all-cause mortality and heart failure-related hospitalisations, but their cost-effectiveness remains controversial. The SCAD programme is a home-based interactive telemonitoring service for HF, which is one of the longest-running and largest telemonitoring programmes for HF in France. The objective of this cost-utility analysis was to evaluate the costeffectiveness of the SCAD programme with respect to standard hospital-based care in patients with HF.

\section{Methods}

A Markov model simulating hospitalisations and mortality in patients with HF was constructed to estimate outcomes and costs. The model included six distinct health states (three 'not hospitalised' states, two 'hospitalisation for heart failure' states, both depending on the number of previous hospitalisations, and one death state. The model lifetime in the base case was ten years. Model inputs were based on published literature. Outputs (costs and QALYS) were compared between SCAD participants and standard care. Deterministic and probabilistic sensitivity analyses were performed to assess uncertainty in the input parameters of the model.

\section{Results}

The number of quality-adjusted life years (QALYs) was 3.75 in the standard care setting and 4.41 in the SCAD setting. This corresponds to a gain in QALYs provided by the SCAD programme of 0.65 over the ten-year lifetime of the model. The estimated total cost was $€ 30,932$ in the standard care setting and $€ 35,177$ in the SCAD setting, with an incremental cost of $€ 4,245$. The incremental cost-effectiveness ratio for the SCAD programme over standard care was estimated at $€ 4,579 /$ QALY. In the deterministic sensitivity analysis, the variables that had the most impact on the ICER were HF management costs. The likelihood of the SCAD programme being considered cost-effective was $90 \%$ at a willingness-to-pay threshold of $€ 11,800$.

\section{Conclusions}

Enrolment of patients into the SCAD programme is highly cost-effective. Extension of the programme to other hospitals and more patients would have a limited budget impact but provide important clinical benefits. This finding should also be taken into account in new public health policies aimed at encouraging a shift from inpatient to ambulatory care.

\section{Background}

The management of patients with chronic heart failure (HF) is challenging due to the occurrence at unpredictable intervals of acute episodes of rapid onset, which can be life-threatening. In addition, patients with HF tend to be elderly and may have reduced mobility due their disease, which can compromise timely and effective follow-up. For these reasons, HF is a promising candidate for the implementation of telemedicine programmes that allow patients to be followed up and managed at home. Such programmes have now been implemented in many different countries for over twenty years. Although the nature of these programmes varies considerably, recent systematic reviews have generally concluded that their implementation can reduce all-cause mortality and heart failure-related hospitalisations [1-4]. Nonetheless, the most recent (2021) practice guidelines of the European Society of Cardiology for the management of HF consider that the usefulness of telemedicine programmes has not been established unequivocally [5]. More research is thus needed to establish which programmes are the most effective and to quantify their benefits.

Although providing important clinical benefits, effective telemedicine programmes carry a cost, and it is thus important to evaluate whether they are cost-effective for the management of HF. A number of economic studies have evaluated clinical outcomes and costs of these programmes [6-17], and provided somewhat inconsistent results. The reasons for this inconsistency may include differences in the nature and intensity of the programmes evaluated, differences in how they are financed and differences in how the economic analyses were performed. Nonetheless, some recent formal cost-effectiveness analyses have indicated that intensive telemonitoring programmes are indeed cost-effective [11, 14, 16]. However, given the variation in the nature of the interventions evaluated, it is difficult to generalise between programmes and countries. Indeed, the costeffectiveness of each individual telemonitoring programme should ideally be evaluated specifically. The present study assesses the cost-effectiveness of one of the longest-running and largest telemonitoring programmes for HF in France.

The SCAD (Suivi Clinique A Domicile) programme is a home-based interactive telemonitoring service for HF established in the French region of Normandy in 2007. The programme is offered to all patients hospitalised for an acute exacerbation of HF, who are entered into the programme prior to discharge. The idea behind the SCAD programme was that patient empowerment, reinforced education and motivational support will reduce the risk of hospitalisation over the long-term and thus reduce the medical and economic burden of heart failure. Over the last ten years, around 1,000 patients in Normandy have been enrolled in this programme. The benefits of the SCAD programme in terms of reduced hospitalisations and mortality have been demonstrated both in a randomised clinical trial $[18,19]$ and in a naturalistic setting [20] 


\section{Methods}

\section{Aim of the study}

The objective of this cost-utility analysis was to evaluate the cost-effectiveness of the SCAD home telemonitoring programme with respect to standard hospital-based care in patients with HF in France.

\section{Study design}

This was a cost-effectiveness analysis comparing the use of the SCAD programme in patients with HF compared with standard care without telemonitoring in the French setting.

Outcomes and costs were generated in a Markov model simulating hospitalisations and mortality in patients with HF. The Markov model was developed in Microsoft Excel (release 2010, Microsoft Inc, USA). The analysis was performed from a collective perspective, taking into account direct medical and non-medical costs borne by the national health insurance $(\mathrm{NHI})$, by complementary private health insurance and by the patient. The analysis complied with the recommendations of the French Health Authorities for economic evaluations of innovative health technologies [21]. A discount rate of $2.5 \%$ was applied, as recommended in these guidelines [21].

\section{SCAD programme}

The SCAD programme is open to patients recently hospitalised for an acute exacerbation of heart failure in one of the participating hospital centres. Patients are enrolled into the programme mainly at the time of discharge from the hospital and remain in the programme for a period of three months, which can be renewed for a further three months if the patient and cardiologist so desire. Each patient is provided with a dedicated programme installed on a tactile pad for entering data and an internet link to the coordinating centre at the hospital. On six days a week (Sunday excluded), the patient enters information on their clinical state (weight, blood pressure and occurrence of cardiac symptoms), lifestyle factors (diet and physical activity), their psychological state and treatment compliance. In order to limit the amount of time that the patient needs to spend at any one-time, different types of information are provided on different days so that a complete evaluation can be made each week. The healthcare team can access the data entered by the patient through a secure internet portal during office hours. Personalised feedback is provided by a dedicated trained HF nurse from the hospital cardiology department through a telephone call or a text message. The data entered by the patient is also analysed in real-time by a risk algorithm in order to identify any risk of acute decompensation, and automatically generate an alert, if necessary (Additional Table 1). This enables the HF nurse to contact the patient, the general practitioner, the cardiologist or the emergency services whenever necessary in order to organise a consultation or a visit to the hospital. The computer interface also provides access for the patient to information and advice on treatment and on leading a healthy lifestyle. In addition, a secure chat tool is available for the patient throughout the duration of the programme which provides them with a direct contact with the care team and access to an information bank about heart failure.

\section{Description of the model}

A Markov model was developed to simulate six distinct health states, classified as 'not hospitalised' (three possible states), 'hospitalisation for heart failure' (two possible states), both depending on the number of previous hospitalisations, and death (one state). The structure of the model is illustrated in Figure 1. Patients entered the model in one of three 'not hospitalised' health states, depending on the number of previous hospitalisations for HF, namely no previous hospitalisation for HF in the previous year, a single previous hospitalisation for HF or multiple previous hospitalisations. The distribution of patients across these three health states was based on the hospitalisation history over the previous year. This was determined from the number of hospitalisations documented in the French nation health insurance database with HF as a primary diagnosis (identifying the reason for hospitalisation) in a population of patients with chronic HF enrolled into a therapeutic education and telemonitoring programme (SCAD) in France between 2009 and 2016 [22]. Hospitalisations for HF were identified using the diagnostic algorithm developed by Tuppin et al. [23]. The characteristics of the patients in this source population is presented in Additional Table 1.

In the next cycle, patients can either remain in the same 'not hospitalised' health state, transit to a hospitalisation state or die. Two hospitalisation states were considered, either a first hospitalisation for HF, or rehospitalisation for HF. From a hospitalisation health state, patients could either revert to the corresponding 'not hospitalised' state or die. Patients could not remain in a hospitalisation health state for more than one cycle and were obliged to transit at the end of the cycle. Death was considered the end state for the model. The cycle length was one month. This was based on the anticipated average duration of hospitalisation for heart failure [24], as patients cannot stay hospitalised for more than one cycle. The time horizon of the analysis was ten years in order to be long enough to capture the effects and direct costs of telemonitoring programme. No intercurrent events such as the occurrence of adverse events were modelled in the absence of information on how these might influence transition probabilities or outcomes.

\section{Model population}

The analysis population modelled corresponded to a hypothetical cohort population of 10,000 adult patients with heart failure. This population size was chosen to match the incidence of first hospitalisation for heart failure derived from the French national health insurance database [25].

\section{Transition probabilities}


Transition probabilities between each health state were based on published literature. For the initial hospitalisation and mortality, these were estimated from data collected in the ODIN study [26]. This was a large, prospective, multicentre French cohort of 3,237 patients recruited by 61 French centres between 2007 and 2010 and followed up until 2013 [26]. For rehospitalisation, the transition probabilities were based on a more recent analysis of data from the French national health insurance database [27]. All-cause mortality rates for the French general population were obtained from the French national statistics office [28]. All transitions used in the model were stratified by age ( $<70$ years and $\geq 70$ years) and by HF severity (New York Heart Association grade) and the transition probabilities in each stratum were adjusted by the relative risk of hospitalisation and death observed in the ODIN study. Patients remained in the same age and severity class throughout the lifetime of the model. All transition probabilities are listed in Table 1.

\section{Interventions compared}

The Markov model compared costs and outcomes between patients participating in a therapeutic education and telemonitoring (SCAD setting) and non-participants (standard care setting). The relative risk of events (hospitalisation or death) for participants compared to non-participants was applied to the transition probabilities in the model. Relative risks were estimated from outcomes reported in a recent study in which 424 SCAD participants were linked to the French national health insurance database [22] (Table 1). In this study, three groups of patients who differed according to the extent of use of the SCAD programme (low, intermediate and high users) were defined by tercile and outcomes in each group analysed over the follow-up period [22]. However, there was no control group of patients with HF not participating in the programme.

The effectiveness of the telemonitoring programme manifests itself as a decrease in the number of hospitalisations and deaths compared to pre-use levels. This decrease varies with the extent of use, being largest in the high users. Since there was no control group of patients with HF not participating in the programme, low users were considered to represent non-participants and attributed a relative risk of effectiveness of 1 . The efficacy of the SCAD programme was expressed as the relative risk of HF-related hospitalisation or of death for intermediate/high users versus low users of SCAD. The relative risks were estimated from Kaplan-Meier analysis of event rates. The survival curves are provided in the Additional Material. It was assumed that effectiveness was constant for the first 60 months of the model, as shown from a proportional hazard analysis of the Kaplan-Meier curves [22]. Over the next five years the SCAD programme was considered to be no longer effective, since no data is available beyond 60 months. These relative risks were then applied to the transition probabilities to generate use-level specific probabilities for intermediate/high users. 
Table 1

Model inputs

\begin{tabular}{|c|c|c|c|c|}
\hline $\mathbf{N}^{\circ}$ & Variable & Category & Value & Source \\
\hline & \multicolumn{4}{|l|}{ Model population } \\
\hline \multirow[t]{2}{*}{1} & Age group & $<70$ years & $56.0 \%$ & SCAD cohort [22] \\
\hline & & $\geq 70$ years & $44.0 \%$ & SCAD cohort [22] \\
\hline \multirow[t]{2}{*}{2} & Severity & NHYA I/II & $61.0 \%^{\mathrm{a}}$ & SCAD cohort [22] \\
\hline & & NHYA III/IV & $39.0 \%$ & SCAD cohort [22] \\
\hline \multirow[t]{2}{*}{3} & Extent of use of programme & Intermediate & $50.4 \%$ & SCAD cohort [22] \\
\hline & & High & $49.6 \%$ & SCAD cohort [22] \\
\hline \multirow[t]{4}{*}{4} & Number of hospitalisations for HF & 0 in previous 12 months & $52.1 \%$ & SCAD cohort [22] \\
\hline & & 1 in previous 12 months & $36.0 \%$ & SCAD cohort [22] \\
\hline & & $\geq 2$ in previous 12 months & $11.9 \%$ & SCAD cohort [22] \\
\hline & Transition probabilities & & & \\
\hline 5 & \multicolumn{2}{|c|}{ Not hospitalised with no previous hospitalisation for HF to first hospitalisation for HF } & 0,006465718 & ODIN study [26] \\
\hline 6 & \multicolumn{2}{|c|}{ Not hospitalised with one previous hospitalisation for HF to rehospitalisation for HF } & 0,016537578 & AMELI study [25] \\
\hline 7 & \multicolumn{2}{|c|}{ Not hospitalised with $\geq 2$ previous hospitalisations for HF to rehospitalisation for HF } & 0,016537578 & AMELI study [25] \\
\hline 8 & \multicolumn{2}{|c|}{ Not hospitalised with no previous hospitalisation for HF to death } & 0,00644676 & ODIN study [26] \\
\hline 9 & \multicolumn{2}{|c|}{ Not hospitalised with one previous hospitalisation for HF to death } & 0,008465564 & ODIN study [26] \\
\hline 10 & \multicolumn{2}{|c|}{ Not hospitalised with $\geq 2$ previous hospitalisations for HF to death } & 0,018058486 & ODIN study [26] \\
\hline 11 & \multicolumn{2}{|c|}{ First hospitalisation for HF to death (assumption) } & 0,008465564 & Equivalent to $n^{\circ} 9$ \\
\hline \multirow[t]{2}{*}{12} & \multicolumn{2}{|c|}{ Rehospitalisation for HF to death (assumption) } & 0,018058486 & Equivalent to $n^{\circ} 10$ \\
\hline & \multicolumn{2}{|l|}{ Adjustment factors (relative risk) } & & \\
\hline \multirow[t]{4}{*}{13} & \multicolumn{2}{|c|}{ Age $<70$ years and NYHA I/II: risk of hospitalisation for HF } & 0.79 & ODIN study [26] \\
\hline & \multicolumn{2}{|c|}{ Age <70 years and NYHA III/IV: risk of hospitalisation for HF } & 1,43 & ODIN study [26] \\
\hline & \multicolumn{2}{|c|}{ Age $\geq 70$ years and NYHA I/II: risk of hospitalisation for HF } & 0,74 & ODIN study [26] \\
\hline & \multicolumn{2}{|c|}{ Age $\geq 70$ years and NYHA III/IV: risk of hospitalisation for HF } & 1,32 & ODIN study [26] \\
\hline \multirow[t]{5}{*}{14} & \multicolumn{2}{|c|}{ Age $<70$ years and NYHA I/II: risk of death } & 0,76 & ODIN study [26] \\
\hline & \multicolumn{2}{|c|}{ Age $<70$ years and NYHA III/IV: risk of death } & 1,48 & ODIN study [26] \\
\hline & \multicolumn{2}{|c|}{ Age $\geq 70$ years and NYHA I/II: risk of death } & 0,71 & ODIN study [26] \\
\hline & \multicolumn{2}{|c|}{ Age $\geq 70$ years and NYHA III/IV: risk of death } & 1,36 & ODIN study [26] \\
\hline & \multicolumn{2}{|l|}{ Efficacy of intervention (relative risk) } & & \\
\hline \multirow[t]{2}{*}{15} & \multicolumn{2}{|l|}{ Risk of hospitalisation for HF } & 0,500 & SCAD cohort [22] \\
\hline & \multicolumn{2}{|l|}{ Risk of death } & 0,535 & SCAD cohort [22] \\
\hline
\end{tabular}

\section{Utilities}

Utilities for the model were taken from a cost-utility analysis of data from the Systolic HF Treatment with the If Inhibitor Ivabradine Trial (SHIFT) [29, 30]. This analysis reported quality of life (QoL) data using the EuroQoL (EQ-5D) questionnaire, which was administered to 5,313 patients. Using the data, a multilevel regression analysis was performed in order to estimate the variation in EQ-5D as a function of age, gender, NYHA class and hospitalisation status [31]. The regression coefficients were used to weight the baseline utility values of the four different patient subgroups (age $<70$ years or $\geq 70$ years, NHYA class I/II or III/IV) and to determine the disutility value for hospitalisation to be used in the Markov model. These derived utility values are presented in Table 2 . 
Table 2

Utility data considered in the model

\begin{tabular}{|ll|}
\hline Description & Baseline utility \\
\hline$<70$ years \& NYHA I/II & 0.788 \\
\hline$<70$ years \& NYHA III/IV & 0.669 \\
\hline$\geq 70$ years \& NYHA I/II & 0.749 \\
\hline$\geq 70$ years \& NYHA III/IV & 0.603 \\
\hline Hospitalisation & -0.212 \\
\hline NYHA: New York Heart Association class. \\
\hline
\end{tabular}

\section{Costs}

Cost inputs were derived from the SCAD cohort. Individual cost items were retrieved from the SNDS for 528 patients included in the database linkage study [32], who were included from 2010 onwards and who survived for at least twelve months. The reason for excluding patients enrolled prior to 2010 was to ensure collection of exhaustive data on healthcare resource utilisation, since complete information has only been available in the database since 2009. Patients with less than one year's follow-up were excluded in order to enable annual costs to be determined accurately. The procedure for cost estimation complied with the guidelines of the French Health Authorities [21]. Hospitalisation costs were estimated using the National Reference System for Hospital Costs (2016 tariffs, applicable at the time the study was initiated), which provides consolidated unit costs for individual stays according to the reason for hospitalisation, defined by ICD-10 diagnostic groups. All costs were adjusted for inflation and are presented as 2021 Euros.

Unit costs for all healthcare resource expenditure items are provided in the Additional Material. Consolidated costs associated with all states in the Markov model are presented in Table 3. Management costs for the three 'not hospitalised' HF states ( 0,1 or $\geq 2$ previous hospitalisations) were estimated from the median community and outpatient costs accrued over the 12 months before enrolment into the SCAD for patients in the 'standard care' setting and over the 12 months after enrolment for patients in the 'SCAD' setting. Only those management costs that differed significantly between the 'SCAD' and the 'standard care' settings were integrated into the model. The cost of hospitalisation was determined individually according to the level of adherence to the SCAD programme (low, intermediate, high). The overall unit hospitalisation cost for patients in the SCAD setting was calculated from costs in the intermediate and high user groups, weighted by the distribution of patients across the two groups. Unit hospitalisation cost for patients in the standard care setting corresponded to that estimated for low users. The end-of-life cost was the cost of palliative care in the last three months before death. The cost of the SCAD programme was based on the tariffs billed by the hospital, which are specified by the national programme for the evaluation of telemedicine of the French Health Ministry (ETAPES programme). For HF, this corresponds to a six-month renewable care package costed at $€ 470$ for six months. This tariff covers $€ 300$ for the supplier, $€ 110$ for the cardiologist and $€ 60$ for therapeutic education. In the model, a monthly cost of $€ 78,33$ was applied over a six-month period.

Table 3

Costs considered in the model

\begin{tabular}{|lll|}
\hline Resource & Time period considered & Unit cost (€2021) \\
\hline Cost of SCAD programme & Monthly for 6 months & $€ 78.33$ \\
\hline Management cost for non-hospitalised patients: standard care & Monthly & $€ 197.81$ \\
\hline Management cost for non-hospitalised patients: SCAD & Monthly & $€ 7,138.29$ \\
\hline HF hospitalisation cost: standard care (low SCAD use) & Individual stay & $€ 5,742.21$ \\
\hline HF hospitalisation cost: SCAD users (weighted ${ }^{1}$ ) & Individual stay & $€ 5,877.70$ \\
\hline HF hospitalisation cost: intermediate SCAD user & Individual stay & $€ 5,604.33$ \\
\hline HF hospitalisation cost: high SCAD user & Individual stay & $€ 20,847.11$ \\
\hline Palliative care cost & Monthly for 3 months before death & \\
\hline HF: heart failure; SCAD: Suivi Clinique A Domicile. & & \\
\hline 1Weighted to take into account the patient mix between high and intermediate users. & \\
\hline
\end{tabular}

\section{Model outputs}

Outcomes were modelled as life-years (LYS), quality-associated life years (QALYs) and total cost for each management strategy (SCAD and standard care). Incremental differences in costs and QALYs between the SCAD programme and standard care were calculated and the incremental costeffectiveness ratio (ICER) derived by dividing the incremental cost by the incremental effectiveness. ICERs were calculated for both QALYs and LYS. 


\section{Sensitivity analysis}

Deterministic and probabilistic sensitivity analyses were performed to assess uncertainty in the input parameters of the model. In the deterministic sensitivity analysis (DSA), key model inputs were varied within their standard errors or $95 \%$ confidence intervals. If empirical data to inform these precision estimates were unavailable, an arbitrary range of $\pm 20 \%$ was applied. The variables used in the deterministic sensitivity analysis (DSA) and the range of values applied are listed in Table 4.

Table 4

Deterministic sensitivity analysis: range of values tested

\begin{tabular}{|c|c|c|c|}
\hline Parameter & Base case value & Lower bound & Upper bound \\
\hline Duration of participation in the SCAD programme (months) & 6 & $-20 \%$ & $+20 \%$ \\
\hline TP No previous hospitalisation for HF to death & 0.00644768 & $-20 \%$ & $+20 \%$ \\
\hline TP One previous hospitalisation for HF to death & 0.00846556 & $-20 \%$ & $+20 \%$ \\
\hline TP Two previous hospitalisations for HF to death & 0.01805849 & $-20 \%$ & $+20 \%$ \\
\hline TP First hospitalisation for HF to death & 0.00846556 & $-20 \%$ & $+20 \%$ \\
\hline TP Rehospitalisation for HF to death & 0.01805849 & $-20 \%$ & $+20 \%$ \\
\hline TP No previous hospitalisation for HF to first hospitalisation for HF & 0.00646572 & $-20 \%$ & $+20 \%$ \\
\hline TP One previous hospitalisation for HF to rehospitalisation for HF & 0.01653758 & $-20 \%$ & $+20 \%$ \\
\hline TP Two previous hospitalisations for HF to rehospitalisation for HF & 0.01653758 & $-20 \%$ & $+20 \%$ \\
\hline TP risk adjustment HF hospitalisation $<70$ years NYHA I/II & 0.79449129 & $-20 \%$ & $+20 \%$ \\
\hline TP risk adjustment HF hospitalisation $<70$ years NYHA III/IV & 1.42820607 & $-20 \%$ & $+20 \%$ \\
\hline TP risk adjustment HF hospitalisation $\geq 70$ years NYHA I/II & 0.74493376 & $-20 \%$ & $+20 \%$ \\
\hline TP risk adjustment HF hospitalisation $\geq 70$ years NYHA III/IV & 1.32353876 & $-20 \%$ & $+20 \%$ \\
\hline TP risk adjustment death $<70$ years NYHA I/II & 0.75652786 & $-20 \%$ & $+20 \%$ \\
\hline TP risk adjustment death $<70$ years NYHA III/IV & 1.4820971 & $-20 \%$ & $+20 \%$ \\
\hline TP risk adjustment death $\geq 70$ years NYHA I/II & 0.70566347 & $-20 \%$ & $+20 \%$ \\
\hline TP risk adjustment death $\geq 70$ years NYHA III/IV & 1.35992249 & $-20 \%$ & $+20 \%$ \\
\hline Relative risk of hospitalisation for $\mathrm{HF}$ due to $\mathrm{SCAD}$ & 0.5 & $-20 \%$ & $+20 \%$ \\
\hline Persistence of effectiveness of SCAD programme (months) & 60 & 90 & 120 \\
\hline Relative risk of death due to SCAD & 0.535 & $-20 \%$ & $+20 \%$ \\
\hline Utility $\geq 70$ years NYHA I/II & 0.74916346 & $-20 \%$ & $+20 \%$ \\
\hline Utility under70 NYHA III/IV & 0.66867953 & $-20 \%$ & $+20 \%$ \\
\hline Utility under70 NYHA I/II & 0.7875012 & $-20 \%$ & $+20 \%$ \\
\hline Utility $\geq 70$ years NYHA III/IV & 0.60302538 & $-20 \%$ & $+20 \%$ \\
\hline HF hospitalisation cost with SCAD & 5742.20612 & $-20 \%$ & $+20 \%$ \\
\hline $\mathrm{HH}$ hospitalisation cost without SCAD & 7138.29262 & $-20 \%$ & $+20 \%$ \\
\hline Management cost without SCAD (monthly) & 197.814822 & $-20 \%$ & $+20 \%$ \\
\hline Management cost with SCAD (monthly) & 268.524233 & $-20 \%$ & $+20 \%$ \\
\hline Palliative care cost & 20847.1056 & $-20 \%$ & $+20 \%$ \\
\hline Discount rate & $2.5 \%$ & $1.5 \%$ & $4 \%$ \\
\hline
\end{tabular}

In the probabilistic sensitivity analysis (PSA), Monte Carlo simulations were performed allowing the values for the model inputs to vary according to their sampling distributions (5,000 iterations). A log-normal distribution was applied for clinical data, a beta distribution for utilities and a gamma distribution for costs. The results of the analysis are expressed as the cost-effectiveness acceptability curve for the net benefit. 
A number of scenario analyses were also performed. Firstly, the model was reiterated in three subgroups of patients categorised by left ventricular ejection fraction (LVEF). These were preserved ejection fraction (pEF: $>50 \%$ of normal), mid-range ejection fraction (mrEF: $40-49 \%$ ) and reduced ejection fraction (rEF: $<40 \%$ ). Transition probabilities for initial hospitalisation and mortality according to LVEF class were based on data from the ODIN cohort [26]. Since rehospitalisation rates according to the type of ejection fraction are not available in the study of the French national health insurance database [27], the same transition probabilities were used for all three LVEF categories as in the principal analysis. Transition probabilities and relative risks of clinical outcomes used in the scenario analyses are provided in the Additional Material.

A second scenario analysis was performed in which the time horizon of the model was set at either five years or for the lifetime of the patient (compared to ten years in the principal analysis). The five-year horizon was chosen as this is the length of time for which the SCAD programme has been shown to be effective at reducing hospitalisation and mortality. 'Lifetime' was considered to be the time period between entry into the model and transition to the death state for each patient.

A third analysis was performed, in which all patients entered the model in the 'not hospitalised after one previous hospitalisation' state. The justification for this is that the SCAD programme is only proposed to patients at the time of hospital discharge. In the base case, patients who enter the model in the 'not hospitalised with no previous hospitalisation' state and who are not hospitalised during the lifetime of the model will never be proposed the SCAD programme. The scenario analysis evaluates a scenario in which all patients are proposed the programme.

The final scenario analysis evaluated the situation in which participation in the SCAD programme was continued over the entire ten-year period over which costs and utilities were determined.

\section{Results}

\section{Utility outcomes}

Over the course of the model, the total number of hospitalisations was 0.749 in the standard care setting and 0.612 in the SCAD setting (Table 5). The number of life years was 5.11 and 6.03 respectively. The number of quality-adjusted life years (QALYs) was 3.75 in the standard care setting and 4.41 in the SCAD setting. This corresponds to a gain in QALYs provided by the SCAD programme of 0.65 over the ten-year lifetime of the model (Table 5).

Table 5

Utility and cost outcomes

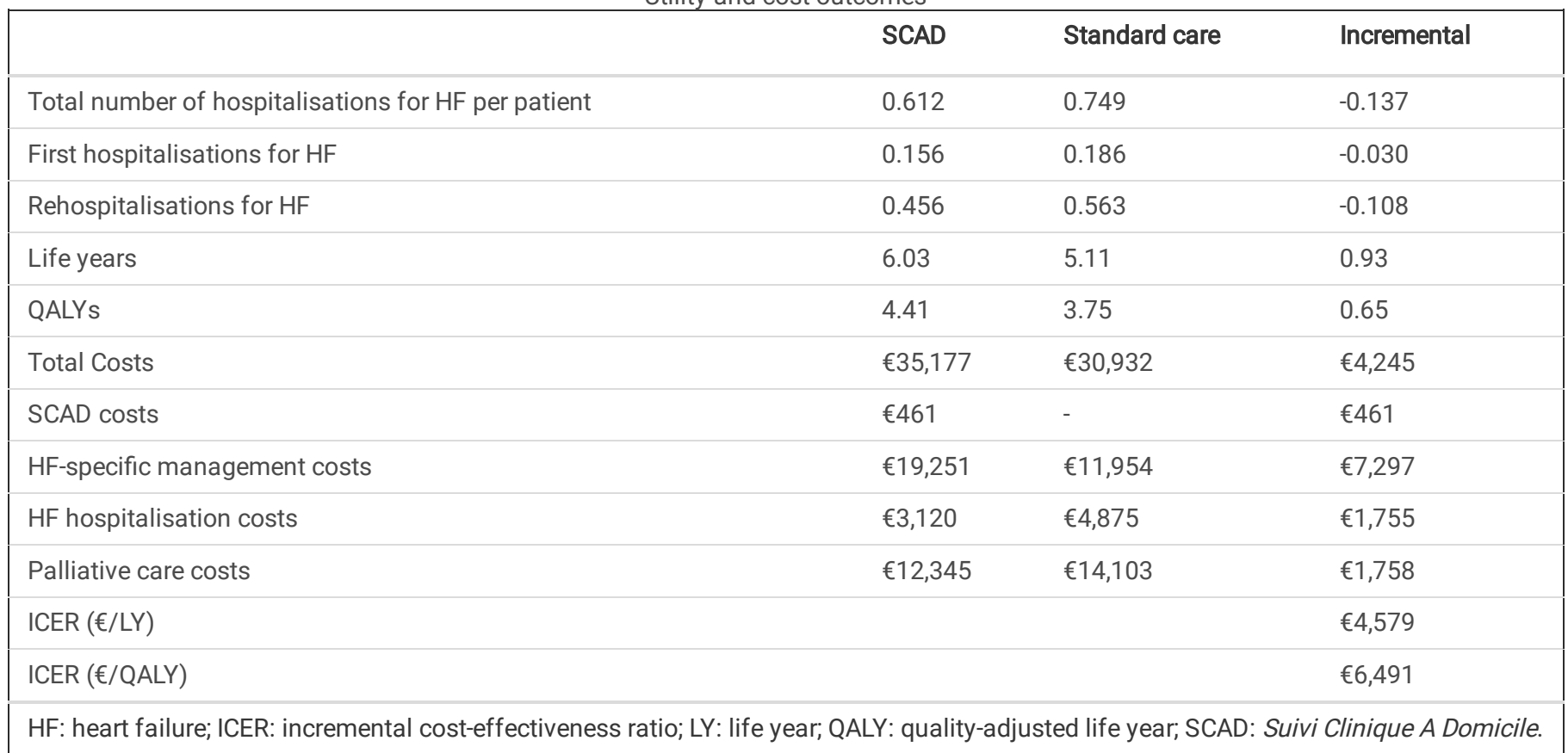

\section{Cost outcomes}

The estimated total cost was $€ 30,932$ in the standard care setting and $€ 35,177$ in the SCAD setting, with an incremental cost of $€ 4,245$ (Table 5). The largest component of costs were the HF-specific management costs, and the higher incremental cost in the SCAD setting was principally due to higher total management costs as the patients survived longer in this setting. The cost of the SCAD programme itself contributed $<2 \%$ of the total cost and around $10 \%$ of the incremental cost (Table 5).

\section{Cost-utility}


The ICER was $€ 4,579$ in terms of incremental cost per life year gained and $€ 6,491$ in terms of incremental cost per quality-adjusted life year gained (Table 5).

\section{Sensitivity analysis}

A deterministic sensitivity analysis was performed to identify variables that influenced the ICER of the SCAD programme compared to standard care. The results are presented in the form of a tornado plot in Figure 2. The variables that had the most impact on the ICER were HF management costs, both in the standard care setting and the SCAD setting. Other variables whose precision influenced the ICER were hospitalisation costs, the utility value for patients aged $\geq 70$ years in NHYA class III/IV and the persistence of the effectiveness of the SCAD programme. Varying the values of the other variables in either direction did not change the estimated ICER by more than €500/QALY.

The effect of increasing the cost of the SCAD programme on the estimated ICER is illustrated in Figure 3 . A one-hundred-fold increase in cost would lead to an increase in the ICER to $€ 76,280$.

In the probabilistic sensitivity analysis, the mean incremental cost of the SCAD programme generated from the Monte Carlo simulations was $€ 4,314$ and the mean incremental utility gained was 0.64 QALYs, corresponding to an ICER for the SCAD programme of $€ 6,689 € / Q A L Y$. These values are very close to those observed in the base-case analysis. A scatter diagram of the outputs from the individual Monte Carlo simulations is presented in Figure 4. The distribution of the outputs was symmetrical and centred on the mean values. It should be noted that in $3 \%$ of simulations, the SCAD strategy was dominant (less expensive and more effective than standard of care). A cost-effectiveness acceptability curve was plotted based on the PSA, which showed that the likelihood of the SCAD programme being considered cost-effective was $90 \%$ at a willingness-to-pay threshold of $€ 11,800$ (Figure 5).

\section{Scenario analyses}

The input data for the three scenario analyses based on subgroups of patients with different LVEF are provided in the supplementary material online. Outcomes are presented in Table 6. The ICERs in the three scenario analyses ranged from $€ 5,843 /$ QALY in patients with preserved ejection fraction to $€ 6,625 / \mathrm{QALY}$ in those with mid-range ejection fraction. Variation in both cost and utility outcome contributed to this difference.

The outputs of the scenario analyses in which the lifetime of the model was varied are presented in Table 7. When a five-year time horizon was used, the SCAD setting was dominant over standard care, being both less expensive and more effective. When the horizon was extended over the entire patient's lifetime, both costs and utilities were higher than in the base case analysis, and the ICER increased by around $20 \%$ from $€ 6,491 / Q A L Y$ to $€ 8,151 /$ QALY.

In the third analysis (Table 8), in which all patients entered the model in the 'not hospitalised after one previous hospitalisation' state, the ICER was around $20 \%$ lower than for the base case ( 5 ,082/QALY). This difference was due both to a reduction in cost and to an increase in life-years gained. This scenario analysis is expected to reflect real-life practice more accurately than the base case analysis.

In the final analysis (Table 9), in which patients participated in SCAD for the entire ten-year lifetime of the model, the additional cost of the SCAD setting over standard care was twice as high as in the base case, but the number of QALYs gained was also somewhat higher. In consequence, the ICER in this scenario analysis was also higher than in the base case (€9,680/QALY).

Table 6

Scenario analysis - according to ejection fraction

\begin{tabular}{|c|c|c|c|c|c|c|c|c|c|c|c|c|}
\hline & \multicolumn{3}{|c|}{ Base case } & \multicolumn{3}{|l|}{$\mathrm{pEF}$} & \multicolumn{3}{|l|}{ mrEF } & \multicolumn{3}{|l|}{$\mathrm{rEF}$} \\
\hline & SCAD & SC & Difference & SCAD & SC & Difference & SCAD & SC & Difference & SCAD & SC & Difference \\
\hline $\begin{array}{l}\text { Life } \\
\text { years }\end{array}$ & 6.03 & 5.11 & 0.93 & 5.88 & 4.87 & 1.01 & 6.19 & 5.29 & 0.90 & 6.00 & 5.03 & 0.97 \\
\hline QALYS & 4.41 & 3.75 & 0.65 & 4.24 & 3.54 & 0.70 & 4.54 & 3.90 & 0.65 & 4.32 & 3.65 & 0.67 \\
\hline $\begin{array}{l}\text { Total } \\
\text { Costs }(€)\end{array}$ & 35,177 & 30,932 & 4,245 & 34,707 & 30,628 & 4,079 & 34,107 & 29,821 & 4,287 & 35,781 & 31,448 & 4,332 \\
\hline $\begin{array}{l}\text { ICER } \\
(€ / L Y)\end{array}$ & & 4579 & & & 4,045 & & & 4,741 & & & 4,474 & \\
\hline $\begin{array}{l}\text { ICER } \\
\text { (€/QALY) }\end{array}$ & & 6491 & & & 5,843 & & & 6,625 & & & 6,431 & \\
\hline
\end{tabular}

mrEF: mid range ejection fraction; ICER: incremental cost-effectiveness ratio; QALY: quality-adjusted life year; pEF: preserved ejection fraction; rEF: reduced ejection fraction; SC: standard care; SCAD: Suivi Clinique A Domicile. 
Table 7

Scenario analysis - according to lifetime of the model

\begin{tabular}{|c|c|c|c|c|c|c|c|c|c|}
\hline & \multicolumn{3}{|c|}{ Base case } & \multicolumn{2}{|c|}{ Five-year horizon } & \multicolumn{4}{|c|}{ Lifetime horizon } \\
\hline & SCAD & SC & Difference & SCAD & SC & Difference & SCAD & SC & Difference \\
\hline Life years & 6.03 & 5.11 & 0.93 & 4.03 & 3.58 & 0.45 & 7.49 & 6.22 & 1.27 \\
\hline QALYS & 4.41 & 3.75 & 0.65 & 2.92 & 2.61 & 0.31 & 5.51 & 4.60 & 0.91 \\
\hline Total Costs $(€)$ & 35,177 & 30,932 & 4,245 & 21,290 & 21,372 & -82 & 45,451 & 38,055 & 7,396 \\
\hline ICER (€/LY) & & 4,579 & & & SCAD dominant & & & 5,841 & \\
\hline ICER (€/QALY) & & 6,491 & & & SCAD dominant & & & 8,151 & \\
\hline
\end{tabular}

Table 8

Scenario analysis - according to number of previous hospitalisations

\begin{tabular}{|lllllll|}
\hline \multicolumn{5}{c}{ Base case } & \multicolumn{3}{c|}{$100 \%$ non-hospitalised patients with one previous hospitalisation } \\
\hline & SCAD & SC & Difference & SCAD & SC & Difference \\
\hline Life years & 6.03 & 5.11 & 0.93 & 5.79 & 4.73 & 1.07 \\
\hline QALYS & 4.41 & 3.75 & 0.65 & 4.23 & 3.47 & 3.76 \\
\hline Total Costs $(€)$ & 35,177 & 30,932 & 4,245 & 36,527 & 32,679 & 3,609 \\
\hline ICER $(€ /$ LY) & & 4,579 & & & 5,082 & \\
\hline ICER $(€ /$ QALY) & & 6,491 & & & \\
\hline ICER: incremental cost-effectiveness ratio; QALY: quality-adjusted life year; SC: standard care; SCAD: Suivi Clinique A Domicile
\end{tabular}

Table 9

Scenario analysis - according to duration of SCAD participation

\begin{tabular}{|c|c|c|c|c|c|c|}
\hline & \multicolumn{3}{|c|}{ Base case (SCAD participation for 6 months) } & \multicolumn{3}{|c|}{ SCAD participation for 10 years } \\
\hline & SCAD & SC & Difference & SCAD & SC & Difference \\
\hline Life years & 6.03 & 5.11 & 0.93 & 6.29 & 5.11 & 1.18 \\
\hline QALYs & 4.41 & 3.75 & 0.65 & 4.59 & 3.75 & 0.84 \\
\hline Total Costs $(€)$ & 35,177 & 30,932 & 4,245 & 39,023 & 30,932 & 8,095 \\
\hline ICER (€/LY) & & 4,579 & & & 6,829 & \\
\hline ICER (€/QALY) & & 6,491 & & & 9,680 & \\
\hline
\end{tabular}

\section{Discussion}

In this cost-effectiveness evaluation of SCAD, a home-based interactive telemonitoring service for HF in France, we identified significant clinical benefits (one life-year gained in the ten years following initiation of the programme in the base case of the model) for a relatively modest cost (€4,245 over the lifetime of the model). The estimated ICER was $€ 6,491 / Q A L Y$. An intervention is considered to be cost-effective when the estimated ICER is below the willingness-to-pay threshold in the given country. While there is no formal willingness-to-pay threshold in France, a threshold of $€ 150,000 /$ QALY has been proposed [33]. The ICER for the SCAD programme is well below this threshold and, in the probabilistic sensitivity analysis, would be below a willingness-to-pay threshold of $€ 11,800$ in $90 \%$ of simulations.

Concerning the benefits of the home telemonitoring programme, in the analysis of SCAD participants in the SNDS database, the rate of unplanned hospitalisations for a cardiovascular diagnosis was halved, the rate of unplanned hospitalisations for HF divided by three, and mortality reduced by around twenty percent [20]. In the present Markov model, these benefits translate into one life-year gained and 0.65 QALYs gained over the time horizon of ten years. These gains can be considered to be clinically important.

With respect to costs, the most expensive component, both with the standard care strategy and with the SCAD strategy, was the management cost of patients with HF who were not hospitalised. This was also the cost item that was associated with the most variability, ranging from zero to >€80,000 for the standard care strategy. Due to this variability, the management cost of non-hospitalised patients was the most important determinant of the 
precision of the ICER estimate. Although the management cost of non-hospitalised patients was higher for the SCAD strategy than for the standard care strategy, this cost differential was partly offset by reduced costs of hospitalisation and palliative care.

The ICER for the SCAD programme varied over the lifetime of the model, increasing with the time horizon applied. This relationship can probably be explained by longer survival of patients included in the programme. These survivors continue to consume healthcare resources for longer, increasing total cost, whereas in standard care, more rapid attrition limits the cost of healthcare over the long term. In contrast, in the absence of data on the effectiveness of the SCAD programme for longer periods, efficacy inputs into the model were identical after five years, and for this reason, utility outcomes after this time would not be expected to differ between strategies. However, even if the time horizon of the model is extended to the patient's entire life expectancy, the ICER remains well below $€ 10,000 / Q A L Y$. When the time-horizon of the model was limited to five years, which is the longest period for which observed data on the impact of the SCAD programme on benefits and costs are available, the SCAD strategy is actually dominant over the standard care strategy, being both more effective in terms of QALYs gained and cost-saving. In the model, a conservative approach was taken in which the benefits of the SCAD programme were limited to the five-year period for which data were available. It is possible that as more long-term data becomes available, estimations of the ICER for time horizons beyond five years may change.

The scenario analyses indicated that the ICER was lower by around ten percent for patients with preserved ejection fraction compared with those with reduced ejection fraction. As a result, SCAD programme appears to be more cost-effective in patients with preserved ejection fraction. This may be explained by the fact that patients with preserved ejection fraction are on average older and have had more previous hospitalizations than patients with reduced ejection fraction. With the availability of more long-term data, it may be possible to evaluate whether participation in the SCAD programme actually slows the decrease in ejection fraction over time in patients with HF.

The scenario analysis in which all patients entered the model in the 'not hospitalised after one previous hospitalisation' state corresponds to how the SCAD programme currently operates, where only patients who are hospitalised are offered participation in the programme. The base case represented a conservative hypothesis, where certain patients are never hospitalised are also included in the model, and who will contribute equally to both the standard care and the SCAD strategy. In the base case, this will have the effect of diluting incremental utility and cost differences between the two strategies. The lower ICER determined in the scenario analysis may for this reason reflect more accurately the cost-effectiveness of the SCAD programme as it is operated today.

Although telemonitoring programmes such as SCAD bear a cost, which is attributable both to the cost of the programme itself and to higher management costs related to longer survival of the patients, this cost is relatively small compared to the total cost to health services of HF. In France, there around 540,000 patients managed for chronic HF, who generated a total cost to national health insurance in 2013 of $€ 1,186$ million [34]. Since SCAD programme is dominant in the short term (between 1 and 5 years), making it available to all patients at the current cost (€470 for 6 months) would generate short-term savings. Indeed, even though the cost of SCAD programme for all these patients would represent an additional cost of $€ 250$ million, the savings generated from the reduction in hospitalizations would reduce total health insurance expenditures. As shown in the final scenario analysis, even when paying for patients to continue in the programme for ten years (rather than for six months as in current practice, modelled in the base case), the estimated ICER remains below €10,000/QALY and the utility benefit is greater.

The current COVID-19 pandemic has illustrated the attractiveness of telemedicine interventions for managing patients with chronic diseases in their homes [35]. Given their clinical efficacy and their cost-effectiveness, it may be expected that home telemonitoring programmes such as SCAD will be introduced in other diseases or extended to other hospitals or regions. It should however be noted that implementation of the SCAD programme bears a specific cost, which needs to be taken into account. In particular, functioning of the programme requires funding for the full-time involvement of a trained nurse dedicated to patient monitoring and alert management.

Comparison of the present findings with those of cost-effectiveness analyses performed in other countries is not straightforward, due to differences in the nature of the telemonitoring programme considered and in how they are financed. Nonetheless, recent studies of intense telemonitoring programmes for heart failure have been consistent in showing them to be cost-effective. For example, a Markov model similar to the present one has been used to evaluate cost-effectiveness of telehealth programs for congestive heart failure in the context of the United States health system [14]. Inputs were derived from a meta-analysis of multiple home telemonitoring programmes [36]. At the five-year time horizon, the authors found that enrolment in such a programme would result in cost savings of $\$ 4,456$ with a gain of 0.50 life years. In the European context, data from the TransEuropean Network-Home-Care Management System (TEN-HMS) study [37] were used in a Markov model involving transitions between different NHYA severity classes [11]. At the twenty-year time horizon, the ICER was estimated to be $€ 12,479 /$ QALY. Most recently, Vesterggard et al. have reported on the TeleCare North HF study in Denmark [16]. This is a telemedicine programme implemented by nurses with a therapeutic education component and remote monitoring of clinical data provided by the patient. This cost-effectiveness analysis was not a modelling study but used real data on utilities and costs collected from patients participating in the programme. This analysis found the telemonitoring strategy to be dominant over standard care, with a net monitory benefit of $£ 5,164$ (approximately $€ 6,100$ ) at a time-horizon of one year. Taken together, the findings of these different studies provide a strong argument that intensive telemedicine programmes are a cost-effective way to manage patients with HF in different healthcare systems.

The study presents certain limitations. The model inputs come from multiple published sources, principally the ODIN study [26] and the SCAD-SNDS cohort [20], and the different source populations may not be fully comparable. In addition, in the SCAD-SNDS cohort, which was used as the source of 
the relative risks of hospitalisation and mortality, there was no control group without home telemonitoring, and the event rates in the low adherence group were used to represent standard care. However, in the SCAD study, even low-level users had lower rehospitalisation rates compared to the period before joining the SCAD programme, suggesting that the low adherence group may gain some benefit from the programme compared to nonparticipants. For this reason, the incremental gain in QALYs compared to standard care may have been underestimated.

\section{Conclusions}

Enrolment of patients into the SCAD programme is highly cost-effective. Extension of the programme to other hospitals and more patients would have a limited budget impact but provide important clinical benefits. This finding should also be taken into account in new public health policies aimed at encouraging a shift from inpatient to ambulatory care.

\section{Abbreviations}

\begin{tabular}{|ll|}
\hline Cl: & Confidence Interval \\
\hline DSA & Deterministic Sensitivity Analysis \\
\hline EF: & Ejection Fraction \\
\hline HF: & Heart Failure \\
\hline HF-mrEF: & Heart Failure with Mid-Range Ejection Fraction \\
\hline HF-pEF: & Heart Failure with Preserved Ejection Fraction \\
\hline HF-rEF: & Heart Failure with Reduced Ejection Fraction \\
\hline HR: & Hazard Ratio \\
\hline ICER: & Incremental Cost-Effectiveness Ratio \\
\hline LL: & Lower Limit \\
\hline LVEF & left ventricular ejection fraction \\
\hline LY: & Life Year \\
\hline mrEF: & Mid Range Ejection Fraction \\
\hline NHI & National Health Insurance \\
\hline NYHA: & New York Heart Association class \\
\hline PSA & Probabilistic Sensitivity Analysis \\
\hline pEF: & Preserved Ejection Fraction \\
\hline QALYs: & Quality-Adjusted Life Years \\
\hline QoL & Quality of Life \\
\hline rEF: & Reduced Ejection Fraction \\
\hline SC: & Standard Care \\
\hline SCAD: & Suivi Clinique A Domicile \\
\hline SHIFT & Systolic HF Treatment with the If Inhibitor Ivabradine Trial \\
\hline TEN-HMS & Trans-European Network-Home-Care Management System \\
\hline TP: & transition probability \\
\hline UL: & Upper Limit \\
\hline
\end{tabular}

\section{Declarations}

\section{Ethics approval and consent to participate}

The study was a modelling study using previously published data and involved no interactions (interventions or data collection) with actual patients.

\section{Consent for publication}


Not applicable.

\section{Availability of data and materials}

All data and software used to construct this model are identified either in the manuscript or in cited source references.

\section{Competing interests}

FB, MC and TdC are employees of Amgen SAS. VD and LC are employees of Cemka. RS, DL, KH, AB and PM have no conflict of interest to declare.

\section{Funding}

This work was funded by Amgen SAS, Boulogne-Billancourt, France, who were involved in planning, conducting, analysing and interpreting the study. Amgen SAS financed the costs associated with the development and publishing of the present manuscript.

\section{Author's contributions}

VD and LC were responsible of collecting source data. MC performed the modelling analysis. MC, RS, DL, LC, VD, FB, TdC, KH, AB and PM participated in the design or implementation of the study. MC, RS, DL, LC, VD, FB, TdC, KH, AB and PM were involved in the analysis and interpretation of the results and the development of this manuscript. MC, RS, DL, LC, VD, FB, TdC, KH, AB and PM had full access to the data and gave final approval before submission.

\section{Acknowledgements}

Medical writing assistance was provided by Adam Doble (Foxymed, Paris, France) and Mégane Caillon (Amgen, Boulogne Billancourt, France).

\section{Previous presentations}

An abstract and poster relating to this work were presented at the European Society of Cardiology Congress 2020 - The Digital Experience (August 2020) [22].

\section{References}

1. Inglis SC, Clark RA, Dierckx R, Prieto-Merino D, Cleland JG. Structured telephone support or non-invasive telemonitoring for patients with heart failure. Cochrane Database Syst Rev. 2015(10):Cd007228.

2. Yun JE, Park JE, Park HY, Lee HY, Park DA. Comparative Effectiveness of Telemonitoring Versus Usual Care for Heart Failure: A Systematic Review and Meta-analysis. J Card Fail. 2018;24(1):19-28.

3. Clark RA. Telehealth in the Elderly with Chronic Heart Failure: What Is the Evidence? Stud Health Technol Inform. 2018;24618-23.

4. Pandor A, Gomersall T, Stevens JW, Wang J, Al-Mohammad A, Bakhai A, Cleland JG, Cowie MR, Wong R. Remote monitoring after recent hospital discharge in patients with heart failure: a systematic review and network meta-analysis. Heart. 2013;99(23):1717-26.

5. McDonagh TA, Metra M, Adamo M, Gardner RS, Baumbach A, Böhm M, Burri H, Butler J, Čelutkienè J, Chioncel O, et al. 2021 ESC Guidelines for the diagnosis and treatment of acute and chronic heart failure: Developed by the Task Force for the diagnosis and treatment of acute and chronic heart failure of the European Society of Cardiology (ESC) With the special contribution of the Heart Failure Association (HFA) of the ESC. European Heart Journal. 2021;42(36):3599-726.

6. Boyne JJ, Van Asselt AD, Gorgels AP, Steuten LM, De Weerd G, Kragten J, Vrijhoef HJ. Cost-effectiveness analysis of telemonitoring versus usual care in patients with heart failure: the TEHAF-study. J Telemed Telecare. 2013;19(5):242-8.

7. Chen YH, Ho YL, Huang HC, Wu HW, Lee CY, Hsu TP, Cheng CL, Chen MF. Assessment of the clinical outcomes and cost-effectiveness of the management of systolic heart failure in Chinese patients using a home-based intervention. J Int Med Res. 2010;38(1):242-52.

8. Chen YH, Lin YH, Hung CS, Huang CC, Yeih DF, Chuang PY, Ho YL, Chen MF. Clinical outcome and cost-effectiveness of a synchronous telehealth service for seniors and nonseniors with cardiovascular diseases: quasi-experimental study. J Med Internet Res. 2013;15(4):e87.

9. de Lusignan S, Wells S, Johnson P, Meredith K, Leatham E. Compliance and effectiveness of 1 year's home telemonitoring. The report of a pilot study of patients with chronic heart failure. Eur J Heart Fail. 2001;3(6):723-30.

10. Frederix I, Vanderlinden L, Verboven AS, Welten M, Wouters D, De Keulenaer G, Ector B, Elegeert I, Troisfontaines P, Weytjens C, et al. Long-term impact of a six-month telemedical care programme on mortality, heart failure readmissions and healthcare costs in patients with chronic heart 
failure. J Telemed Telecare. 2019;25(5):286-93.

11. Grustam AS, Severens JL, De Massari D, Buyukkaramikli N, Koymans R, Vrijhoef HJM. Cost-Effectiveness Analysis in Telehealth: A Comparison between Home Telemonitoring, Nurse Telephone Support, and Usual Care in Chronic Heart Failure Management. Value Health. $2018 ; 21(7): 772-82$.

12. Henderson C, Knapp M, Fernández JL, Beecham J, Hirani SP, Cartwright M, Rixon L, Beynon M, Rogers A, Bower P, et al. Cost effectiveness of telehealth for patients with long term conditions (Whole Systems Demonstrator telehealth questionnaire study): nested economic evaluation in a pragmatic, cluster randomised controlled trial. Bmj. 2013;346f1035.

13. Jiménez-Marrero S, Yun S, Cainzos-Achirica M, Enjuanes C, Garay A, Farre N, Verdú JM, Linas A, Ruiz P, Hidalgo E, et al. Impact of telemedicine on the clinical outcomes and healthcare costs of patients with chronic heart failure and mid-range or preserved ejection fraction managed in a multidisciplinary chronic heart failure programme: A sub-analysis of the iCOR randomized trial. J Telemed Telecare. 2020;26(1-2):64-72.

14. Liu SX, Xiang R, Lagor C, Liu N, Sullivan K. Economic Modeling of Heart Failure Telehealth Programs: When Do They Become Cost Saving? Int J Telemed Appl. 2016;20163289628.

15. Smith B, Hughes-Cromwick PF, Forkner E, Galbreath AD. Cost-effectiveness of telephonic disease management in heart failure. Am J Manag Care. 2008;14(2):106-15.

16. Vestergaard AS, Hansen L, Sørensen SS, Jensen MB, Ehlers LH. Is telehealthcare for heart failure patients cost-effective? An economic evaluation alongside the Danish TeleCare North heart failure trial. BMJ Open. 2020;10(1):e031670.

17. Pandor A, Thokala P, Gomersall T, Baalbaki H, Stevens JW, Wang J, Wong R, Brennan A, Fitzgerald P. Home telemonitoring or structured telephone support programmes after recent discharge in patients with heart failure: systematic review and economic evaluation. Health Technol Assess. 2013;17(32):1-207, v-vi.

18. Coutance G, Belin A, Biannic C, Parienti JJ, Loiselet P, Michel L, Pradere G, Milliez PU, Grollier G, Sabatier R. P1092- Educative telemedicine reduces the severity of rehospitalizations for acute heart failure in an elderly population: post-hoc analysis of SEDIC study. European Journal of Heart Failure 2013;12(S1):S144.

19. Sabatier R, Coutance G, Belin A, Biannic C, Loiselet P, Pradere G, Michel L, Parienti JJ, Grollier G. P666 - Three months educational remote telemonitoring in elderly patients with heart failure reduces hospitalizations for acute heart failure at one year: a randomized trial. European Journal of Heart Failure 2013;12(S1):S313.

20. Sabatier R, Jodar M, Legallois D, Courouve L, Donio V, Boudevin F, de Chalus T, Hauchard K, Belin A, Milliez PU. Impact of educational home telemonitoring on hospitalisation and mortality in patients with heart failure in Normandy: a 10-year retrospective study.

21. Haute Autorité de Santé. Choix méthodologiques pour l'évaluation économique à la HAS. 2020.

22. Sabatier R, Legallois D, Jodar M, Donio V, Courouve L, Hauchard K, Boudevin F, De Chalus T, Belin A, Milliez P. Cost-effectiveness analysis of a telemonitoring program on patients with heart failure in Normandy: an 8-year retrospective analysis (2009-2017). Eur Heart J. 2020;41(Supplement 2):ehaa946.3468.

23. Tuppin P, Cuerq A, de Peretti C, Fagot-Campagna A, Danchin N, Juilliere Y, Alla F, Allemand H, Bauters C, Drici MD, et al. Two-year outcome of patients after a first hospitalization for heart failure: A national observational study. Arch Cardiovasc Dis. 2014;107(3):158-68.

24. McMurray JJ, Andersson FL, Stewart S, Svensson K, Solal AC, Dietz R, Vanhaecke J, van Veldhuisen DJ, Ostergren J, Granger CB, et al. Resource utilization and costs in the Candesartan in Heart failure: Assessment of Reduction in Mortality and morbidity (CHARM) programme. Eur Heart J. 2006;27(12):1447-58.

25. Tuppin P, Cuerq A, de Peretti C, Fagot-Campagna A, Danchin N, Juilliere Y, Alla F, Allemand H, Bauters C, Drici MD, et al. First hospitalization for heart failure in France in 2009: patient characteristics and 30-day follow-up. Arch Cardiovasc Dis. 2013;106(11):570-85.

26. Juilliere Y, Jourdain P, Suty-Selton C, Beard T, Berder V, Maitre B, Trochu JN, Drouet E, Pace B, Mulak G, et al. Therapeutic patient education and allcause mortality in patients with chronic heart failure: a propensity analysis. Int J Cardiol. 2013;168(1):388-95.

27. Feldman SF, Lesuffleur T, Olie V, Gastaldi-Menager C, Juilliere Y, Tuppin P. French annual national observational study of 2015 outpatient and inpatient healthcare utilization by approximately half a million patients with previous heart failure diagnosis. Arch Cardiovasc Dis. 2021;114(1):17-32.

28. Institut National d'Etudes Demographiques. Mortality rates by sex and age in 20182020 [Available from: https://www.ined.fr/en/everything_about_population/data/france/deaths-causes-mortality/mortality-rates-sex-age/.

29. Swedberg K, Komajda M, Bohm M, Borer J, Robertson M, Tavazzi L, Ford I, Investigators S. Effects on outcomes of heart rate reduction by ivabradine in patients with congestive heart failure: is there an influence of beta-blocker dose?: findings from the SHIFT (Systolic Heart failure treatment with the I(f) inhibitor ivabradine Trial) study. J Am Coll Cardiol. 2012;59(22):1938-45.

30. Griffiths A, Paracha N, Davies A, Branscombe N, Cowie MR, Sculpher M. The cost effectiveness of ivabradine in the treatment of chronic heart failure from the U.K. National Health Service perspective. Heart. 2014;100(13):1031-6.

31. Griffiths A, Paracha N, Davies A, Branscombe N, Cowie MR, Sculpher M. Analyzing Health-Related Quality of Life Data to Estimate Parameters for Cost-Effectiveness Models: An Example Using Longitudinal EQ-5D Data from the SHIFT Randomized Controlled Trial. Adv Ther. 2017;34(3):75364. 
32. Courouve L, Joda M, Gabbas M, Legallois D, Donio V, Sabatier R. Appariement probabiliste au Système national des données de santé d'un programme de télésurveillance à domicile des patients atteints d'insuffisance cardiaque en Normandie. Rev Epidémiol Santé Publique. 2020;68(Suppl. 1):S39.

33. Téhard B, Detournay B, Borget I, Roze S, De Pouvourville G. Value of a QALY for France: A New Approach to Propose Acceptable Reference Values. Value Health. 2020;23(8):985-93.

34. Tuppin P, Rivière S, Rigault A, Tala S, Drouin J, Pestel L, Denis P, Gastaldi-Ménager C, Gissot C, Juillière Y, et al. Prevalence and economic burden of cardiovascular diseases in France in 2013 according to the national health insurance scheme database. Arch Cardiovasc Dis. 2016;109(6-7):399411.

35. Cleland JGF, Clark RA, Pellicori P, Inglis SC. Caring for people with heart failure and many other medical problems through and beyond the COVID19 pandemic: the advantages of universal access to home telemonitoring. Eur J Heart Fail. 2020;22(6):995-8.

36. Xiang R, Li L, Liu SX. Meta-analysis and meta-regression of telehealth programmes for patients with chronic heart failure. J Telemed Telecare. 2013;19(5):249-59.

37. Cleland JG, Louis AA, Rigby AS, Janssens U, Balk AH, Investigators T-H. Noninvasive home telemonitoring for patients with heart failure at high risk of recurrent admission and death: the Trans-European Network-Home-Care Management System (TEN-HMS) study. J Am Coll Cardiol. 2005;45(10):1654-64.

\section{Figures}

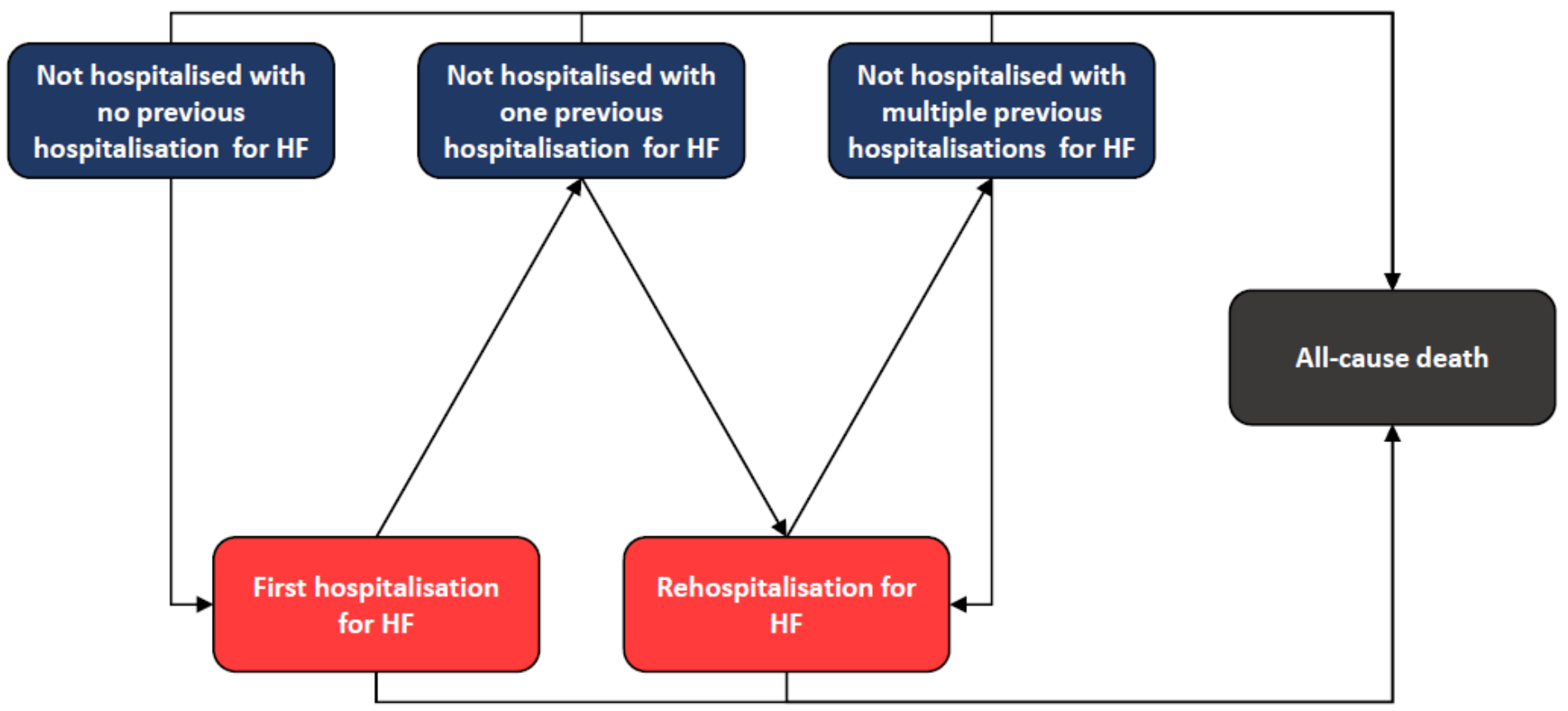

\section{Figure 1}

Structure of the Markov model 


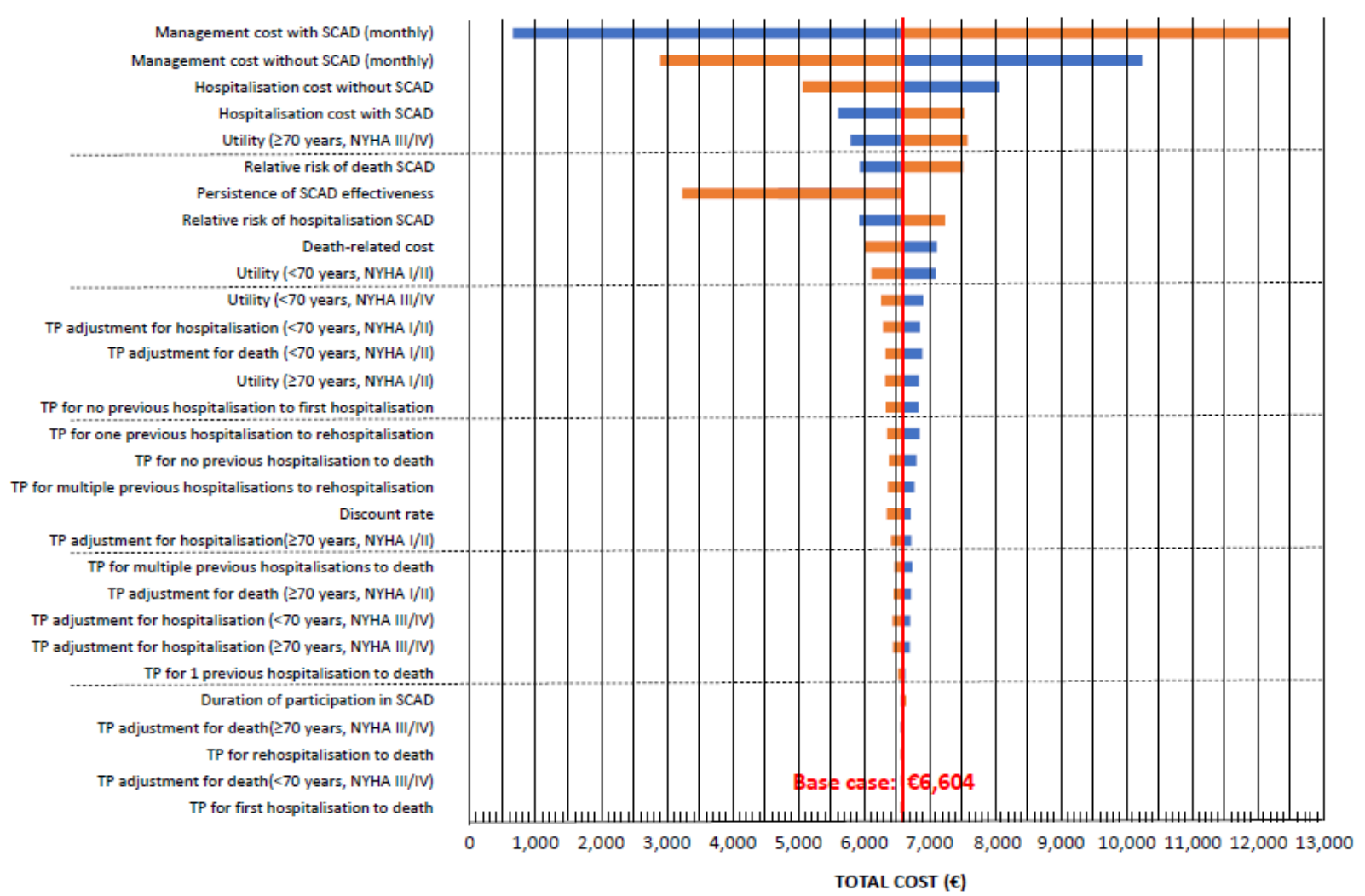

Figure 2

Deterministic sensitivity analysis Blue: lower limit of uncertainty; red: upper limit of uncertainty. All hospitalisation items in this analysis are restricted to hospitalisations for heart failure, as specified in Table 4.

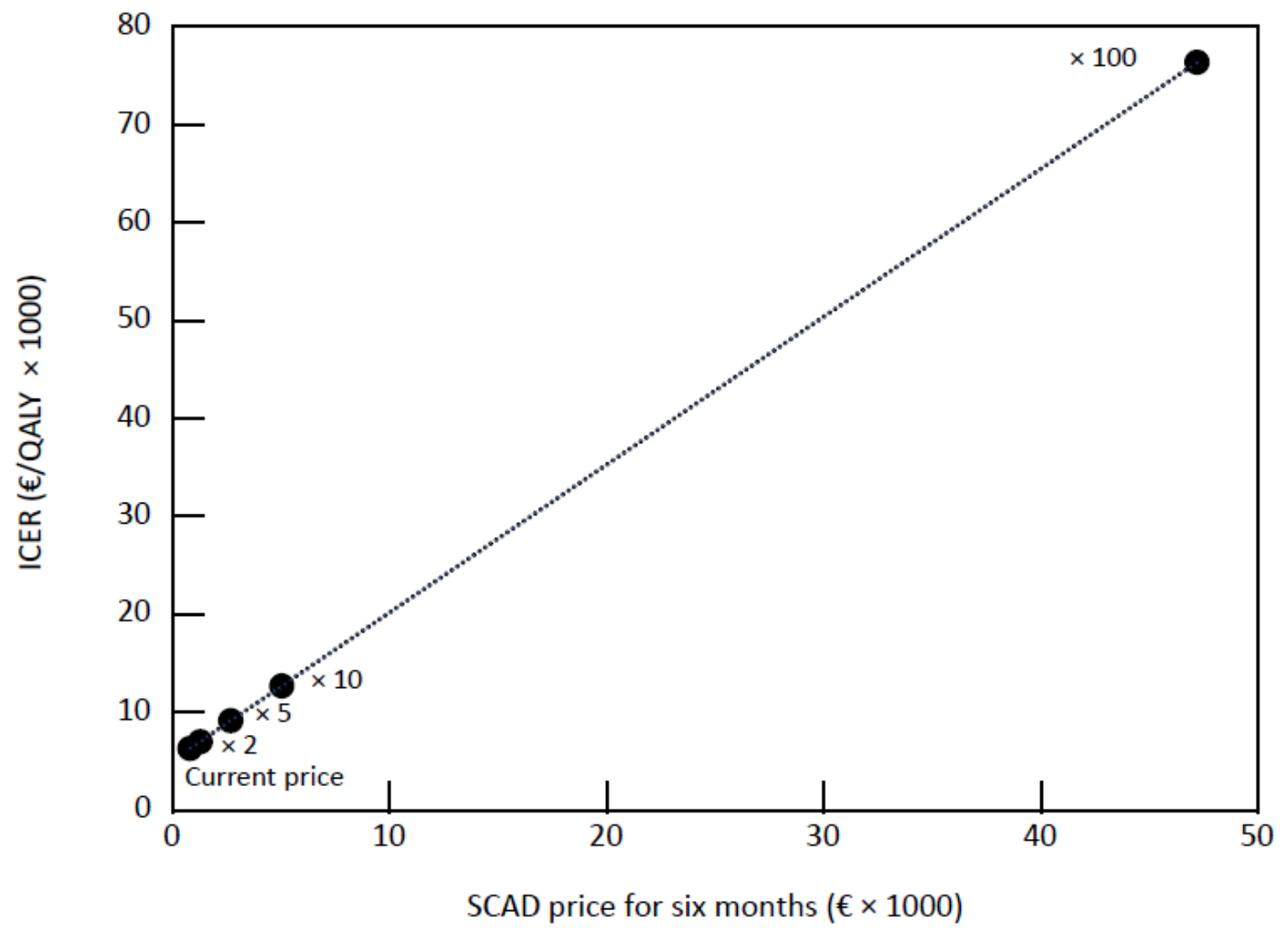

Figure 3

Effect on the ICER of varying SCAD cost 


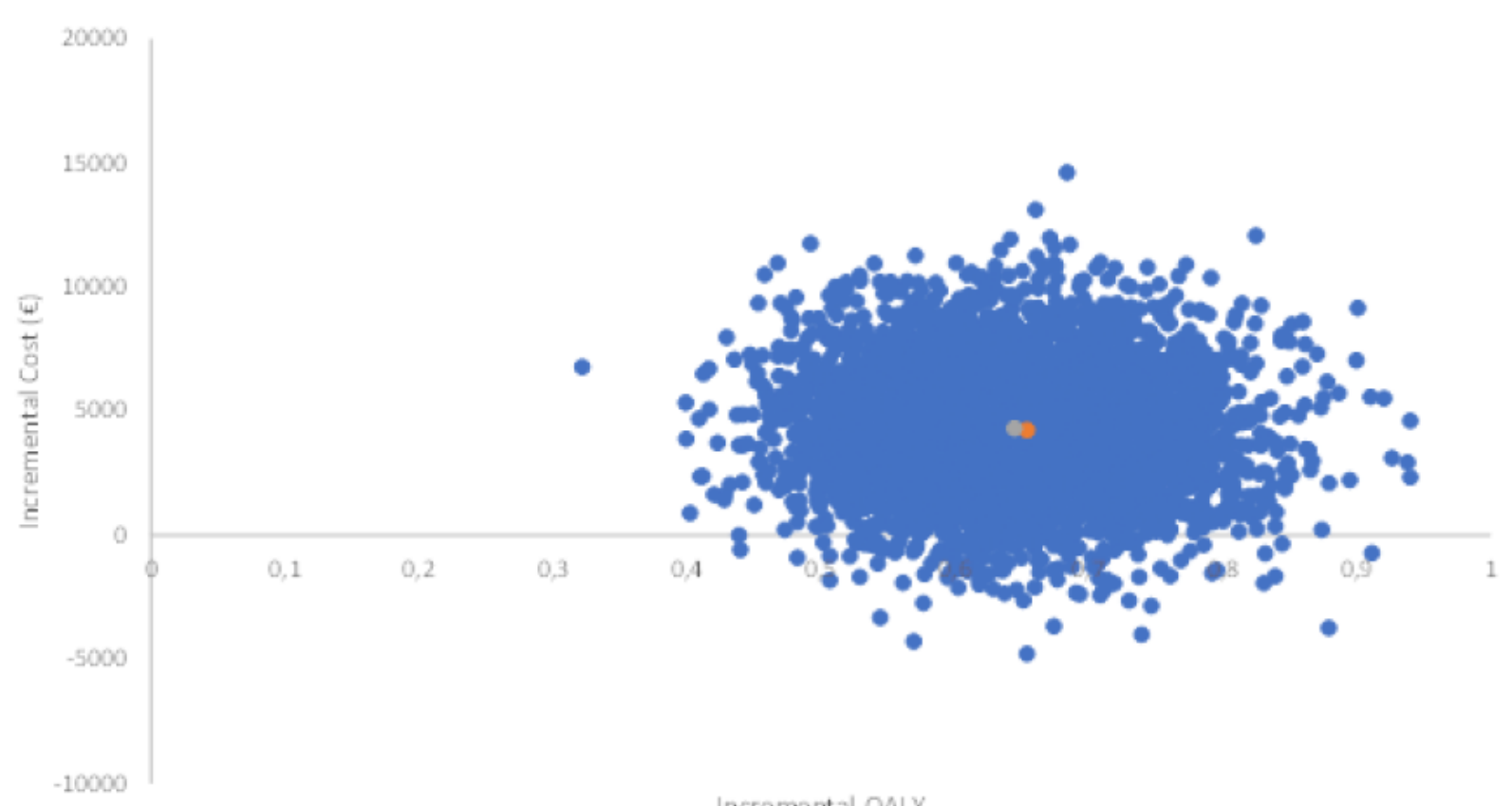

Incremental QALY

\section{Figure 4}

Probabilistic sensitivity analysis Each blue point represents the incremental cost $(€)$ and utility (QALY) of the SCAD programme from an individual Monte Carlo simulation. The grey point represents the mean incremental cost and utility derived from all Monte Carlo simulations and the orange point the incremental cost and utility derived from the deterministic base case analysis.

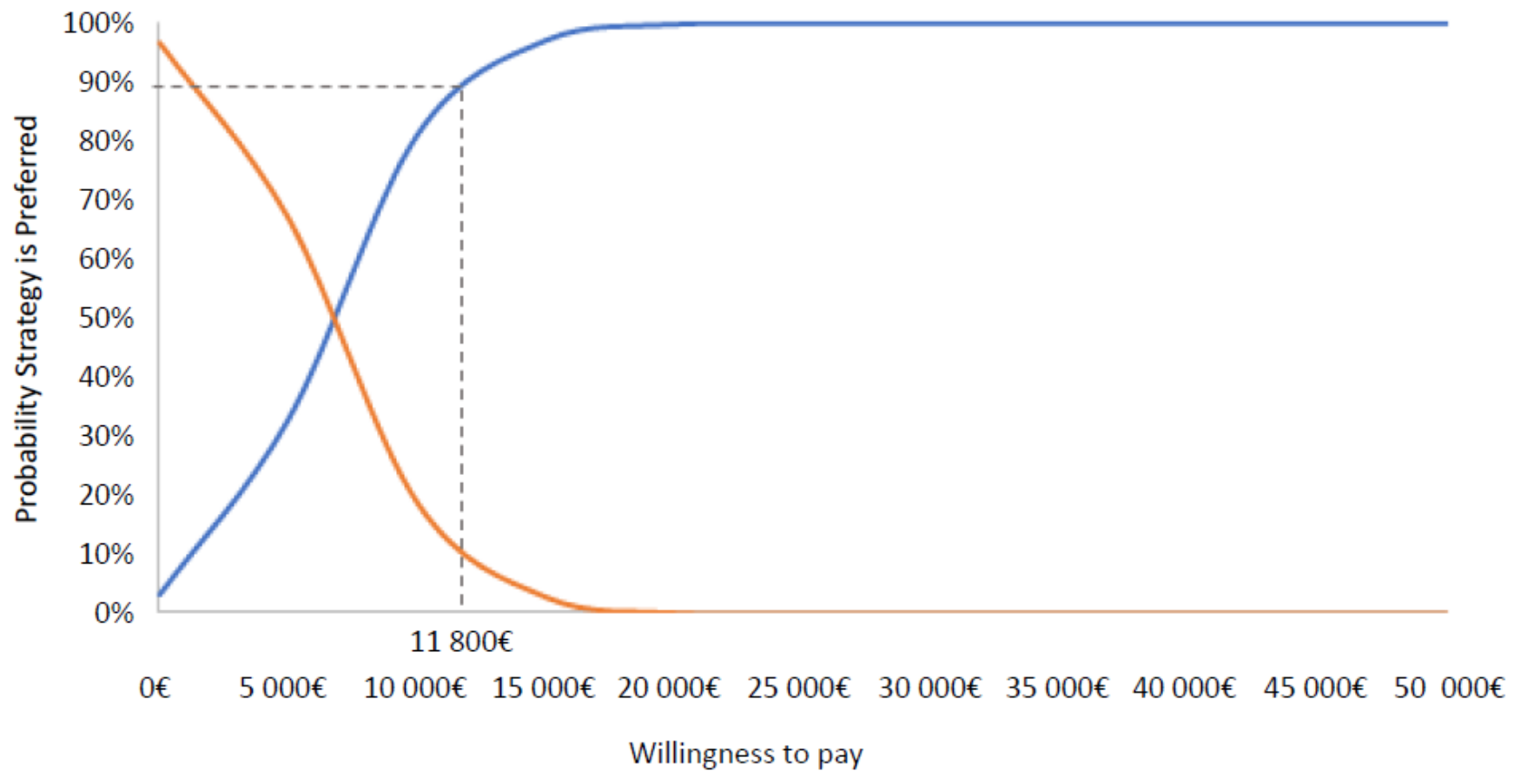

\section{Figure 5}

Willingness to pay thresholds Blue curve: SCAD programme; orange curve: standard care.

\section{Supplementary Files}

This is a list of supplementary files associated with this preprint. Click to download.

- SCADCEAdditionalfile1.docx

- SCADCEAdditionalfile2.docx 
- SCADCEAdditionalfile3.docx

- SCADCEAdditionalfile4.docx

- SCADCEAdditionalfile5.docx

Page 18/18 